\title{
Faculty of Engineering
}

Faculty Publications

This is a post-print version of the following article:

Effects of different analysis techniques and recording duty cycles on passive acoustic monitoring of killer whales

Amalis Riera, John K. Ford, \& N. Ross Chapman

August 2013

The final publication is available at:

https://doi.org/10.1121/1.4816552

\section{Citation for this paper:}

Riera, A., Ford, J. K., \& Chapman, N. R. (2013). Effects of different analysis techniques and recording duty cycles on passive acoustic monitoring of killer whales. The Journal of the Acoustical Society of America, 134(3), 2393-2404. https://doi.org/10.1121/1.4816552. 


\section{Effects of different analysis techniques and recording duty cycles on passive \\ acoustic monitoring of killer whales ${ }^{\mathrm{a}}$}

3

4

5

6

7

8

9

10

11

12

13

14

15

16

17

18

19

20

21

22

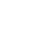

\author{
Amalis Riera ${ }^{\mathrm{b}}$ and N. Ross Chapman \\ University of Victoria, School of Earth and Ocean Sciences, Bob Wright Centre A405, 3800 \\ Finnerty Rd, Victoria, British Columbia, V8P5C2, Canada. \\ John K. Ford \\ Cetacean Research Program, Pacific Biological Station, Nanaimo, British Columbia, V9T 6N7, \\ Canada.
}

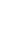

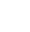

1

2

(Dated: 18 May 2012)

3

\footnotetext{
${ }^{\mathrm{a}}$ This paper is intended for the special issue on Marine Mammals and Passive Acoustics.

${ }^{\mathrm{b}}$ Author to whom correspondence should be addressed. Electronic mail: ariera@uvic.ca
} 
2 Killer whales in British Columbia are at risk, and little is known about their winter distribution.

3 Passive acoustic monitoring of their year-round habitat is a valuable supplemental method to

4 traditional visual and photographic surveys. However, long-term acoustic studies of odontocetes

5 have some limitations, including the generation of large amounts of data that require highly time-

6 consuming processing. There is a need to develop tools and protocols to maximize the efficiency

7 of such studies. Here, two types of analysis, Real-Time and Long Term Spectral Averages, were

8 compared to assess their performance at detecting killer whale calls in long-term acoustic

9 recordings. In addition, two different duty cycles, $1 / 3$ and 2/3, were tested. Both the use of Long

10 Term Spectral Averages and a lower duty cycle resulted in a decrease in call detection and

11 positive pod identification, leading to underestimations of the amount of time the whales were

12 present. The impact of these limitations should be considered in future killer whale acoustic

13 surveys. A compromise between a lower resolution data processing method and a higher duty

14 cycle is suggested for maximum methodological efficiency.

PACS numbers: 43.80.Jz, 43.80.-n 
1

\section{INTRODUCTION}

Passive acoustic monitoring (PAM) has been increasingly used in cetacean research for population assessment and risk mitigation (Rayment et al., 2011, Sirovic and Hildebrand, 2011, Kyhn et al., 2012). The present study investigates the application of long-term PAM techniques to study killer whale (Orcinus orca) year-round distribution and habitat use in coastal waters of the northeastern Pacific.

(n)

Coastal waters of the northeastern Pacific are home to three distinct lineages of killer whales: the fish-eating Residents, the mammal-eating Transients and the shark-eating Offshores (Ford et al., 1998, Baird, 2001, Dahlheim et al., 2008, Ford et al., 2011). In addition to diet, they differ morphologically, genetically, behaviorally and acoustically (Ford, 1989, Hoelzel et al., 1998, Deecke et al., 2005, Morin et al., 2010). Resident killer whales live in stable social groups of which the basic social unit is the matriline, which consists of a female and her offspring (Bigg et al., 1990). Related matrilines that travel together the majority of their time are referred to as pods, and pods that associate are grouped into communities. Two communities of Residents coexist in partly overlapping ranges without mixing or interacting: the Northern and Southern Residents. The distribution and movement patterns of Resident and Transient killer whales have been studied extensively over the past 35 years in inshore waters off the east coast of Vancouver Island and in Puget Sound, but little is known about their distribution during the winter and what areas are important for their survival during these months (Ford, 2006).

Killer whales produce three different types of vocalizations: whistles, echolocation clicks and pulsed calls (Ford, 1989). Each killer whale pod possesses a unique repertoire of stereotyped 
1 calls known as its acoustic dialect (Ford, 1991). Pods whose dialects have calls in common are

2 included in the same acoustic clan. Owing to these distinct vocalizations, it is possible to identify

3 the population, clan and sometimes the pod that is being heard in acoustic recordings. Therefore,

4 long-term PAM provides a useful alternative to visual surveys for studying killer whale

5 distribution and occurrence, overcoming the challenges and costs of visual surveys in non-

6 summer months.

7

8 Long-term monitoring studies using autonomous recorders provide valuable information on

9 movement patterns, habitat use and seasonality that is not available with short sampling periods.

10 However, large amounts of data are generated that would require very time-consuming analysis

11 to inspect in real time. New techniques such as automatic detection via neural networks (Brown

12 and Miller, 2007, Matzner et al., 2011) and manual detection tools such as Long Term Spectral

13 Averages (LTSAs; Wiggins and Hildebrand, 2007) have been developed to increase the

14 efficiency of data analysis by reducing the amount of time required to detect significant acoustic

15 events. The LTSA technique has been used to detect marine mammal vocalizations in long-term

16 passive recordings off the Washington coast to assess the impact of increasing the range of

17 military exercises (Oleson et al., 2009). That study included killer whale detections, although

18 they were not the main target. The present paper describes a methodology to monitor killer whale

19 occurrence using an autonomous recorder and apply the LTSA technique to detect and identify

20 killer whale vocalizations.

21

22 Recurring detections of killer whale populations that are "at risk" in a given location can indicate

23 habitat use and identify important areas for management and protection. Ford (2006) used the 
concept of an encounter to quantify the presence of killer whales at a site. An encounter was

2 defined as the positive identification of members of one or more killer whale matrilines, pods or

3 clans at a single location on a given day. Here we suggest a new definition of an acoustic

4 encounter that represents an estimation of whale presence at a finer scale than number of days

5 with detections.

6

7 Acoustic signal measurements or detections can be affected by acoustic sampling decisions. For

8 example, for species that produce whistles with fundamental frequencies extending into the

9 ultrasonic range, an insufficient bandwidth range may result in some whistles being missed

10 (Oswald et al., 2004). It can also lead to an inaccurate classification of whistles to species. For

11 killer whales, a band including frequencies from 0 to at least $8 \mathrm{kHz}$ is needed to adequately

12 identify their pulsed calls (Ford, 1987). Since autonomous recorders offer a limited storage

13 capacity and sampling rate cannot be reduced below $16 \mathrm{kHz}$ when recording killer whales, a duty

14 cycle is required to extend recording time. Killer whales don’t vocalize continuously, so an

15 insufficient duty cycle may result in some calls being missed, which may in turn lead to poor call

16 identification and underestimations of the amount of time the whales are present. Here, the

17 detection and identification performance of two different duty cycles, $1 / 3$ and 2/3, was

18 compared.

19

20 The objectives of this study were 1) to evaluate the performance of the LTSA technique for

21 detecting killer whale vocalizations within a long-term passive acoustic recording by testing it

22 with data collected off southwestern Vancouver Island, and 2) to examine the effects of 
1 decreasing the duty cycle of the acoustic recorder on number of detections, amount of time the

2 whales are heard, and acoustic identification of populations or pods.

\section{MATERIAL AND METHODS}

\section{A. Study site}

6 Acoustic recordings were obtained at Swiftsure Bank (48 $31^{\prime}$ N, $124^{\circ} 56^{\prime}$ W), off the west coast

7 of Vancouver Island, British Columbia, Canada (Fig. 1). Swiftsure Bank is an area of around 150

$8 \mathrm{~km}^{2}$ located approximately $35 \mathrm{~km}$ southwest of Vancouver Island, about $25 \mathrm{~km}$ west from the

9 entrance of the Juan de Fuca strait, or 30 km northwest of Cape Flattery. Deep offshore

10 submarine canyons join the continental shelf in this area, creating abrupt changes in seafloor

11 topography and dramatically reducing water depth to as shallow as $40 \mathrm{~m}$ (Fisheries and Oceans

12 Canada, 2005). Ocean currents along the deep canyons rise towards the surface as they encounter

13 these physical barriers, carrying colder waters rich in nutrients to the shallower waters of the

14 continental shelf. The upwelling enables proliferation of plankton which in turn sustains the

15 development of a rich and diverse ecosystem that includes many species of fishes such as

16 salmon, halibut, rockfish, herring and lingcod. In particular, the presence of salmon makes this

17 area a potential feeding ground for Resident killer whales.

\section{B. Acoustic recording instrument}

20 An AURAL-M2 (Autonomous Underwater Recorder for Acoustic Listening-Model 2, CMulti

21 Électronique Inc.) was used to acquire acoustic data (Multi-Électronnique (MTE) Inc., 2012). 
1 The AURAL was moored to the seafloor at a depth of $72 \mathrm{~m}$, and the hydrophone stood about 10

$2 \mathrm{~m}$ above the seafloor.

3

4 The instrument contained 128 alkaline D-cell batteries, providing a capacity of 328 amp-hours. It

5 contained a 250 GB hard drive to store the sound files in WAV format. The hydrophone was a

6 HTI-96-MIN, which has a nominal sensitivity of $-164.4 \mathrm{~dB}$ re $1 \mathrm{~V} / \mu \mathrm{Pa}( \pm 1 \mathrm{~dB})$ between $10 \mathrm{~Hz}$

7 and $8 \mathrm{kHz}$. The sampling rate was set to 16,384 Hz, which provided a usable audio frequency

8 range of $10-8192 \mathrm{~Hz}$ ). The A/D voltage conversion was 16 bits, supply voltage was 12 VDC

9 nominal (calibrated at $9 \mathrm{VDC}$ ), and amplifier gain was $16 \mathrm{~dB}$. The instrument was programmed

10 on a 2/3 duty cycle, recording 10-minute samples every 15 minutes (i.e., 10 minutes on and 5

11 minutes off).

12

13 The AURAL-M2 was deployed on 23 July 2009, and was recovered on 23 September 2009.

14 Here, data collected throughout August 2009 will be used to compare the performance of the

15 LTSA against Real-Time analysis, and to evaluate the impact of using a lower duty cycle.

16

\section{C. Data analysis}

18 Recovered acoustic data were analysed to detect killer whale vocalizations. The audio files were 19 processed with a Matlab application called Triton to create a Long Term Spectral Average

20 (LTSA; Wiggins and Hildebrand, 2007). An LTSA visually represents a given portion of data

21 (i.e., 1 hour of recordings) in the form of a time series of averaged spectra (Fig. 2). Successive

22 spectra are calculated and averaged together (Wiggins and Hildebrand, 2007), and a time series

23 of the spectra is obtained by sequentially arranging the averaged-spectra. The resolution of the 
1 resulting plot and the data compression factor depend on the averaging time, which is chosen

2 before creating an LTSA.

3

4 The parameters used to create LTSAs were $5 \mathrm{~s}$ time average and $16 \mathrm{~Hz}$ frequency bin size. Each

5 LTSA contained around 2,000 sound files (about a month of acoustic samples) for the 2/3 duty

6 cycle data.

7

8 When killer whale vocalizations were detected on the LTSA, the portions of original data were

9 expanded and visually and aurally analyzed in 10-second spectrogram windows. Call types were

10 identified using a reference catalogue of spectrograms of killer whale calls (Ford, 1987) and a

11 digitized visual and acoustic catalogue of call types (J. Ford, personal communication). Only

12 pulsed calls were used for identification (ID), not echolocation clicks or whistles. ID was

13 attempted at the highest possible resolution (from broadest classification to finest: ecotype, 14 community, clan, pod).

\section{Killer whale acoustic encounter}

17 The number of days with detection of killer whale vocalizations provides an indication of their use of the area: how frequently they visit Swiftsure Bank. The duration of visits at the site also

19 reveals its importance to killer whales. The amount of time they spend in the area was estimated by organizing acoustic killer whale detections into "encounters".

22 During visual surveys using photo-identification of individuals, an encounter starts from the 23 moment a group of killer whales is spotted and ends when the monitoring vessel leaves the 
1 scene. For PAM, an encounter begins when the first call is detected but determining its end

2 requires the application of new criteria since the interpretation of the events relies mostly on

3 presence or absence of sound. There are certainly occasions where whales are present but not

4 detected because they are not vocalizing, they are beyond the hydrophone's detection range, the

5 calls are masked by background noise or the hydrophone is at the duty cycle stage of not

6 recording. All these limitations must be accounted for when delimiting an encounter.

8 A killer whale acoustic encounter was therefore defined as an acoustic event corresponding to a

9 portion of the data in which the same group of killer whales is heard over a sequential number of

10 files, allowing for a given number of files not containing calls within the encounter. The

11 threshold number of files without calls used to discriminate between same and a new encounter

12 was different for Residents and Transients due to the differences in their vocal behaviour (Ford,

13 1989, Deecke et al., 2005).

15 Previous to this organization of call detections into encounters, a preliminary analysis of the data 16 was conducted, focusing mainly on the number of days when killer whale calls were found and

17 the groups that were identified. No rigorous annotation of every sample containing calls was

18 made at this time. However, a subjective sense of the general duration of periods with calls was 19 gained. Resident calls were frequently detected in a larger number of successive samples than 20 Transient calls, which is consistent with Deecke et al.'s (2005) findings that Transients vocalize 21 significantly less often than Residents. Deecke et al. (2005) reported median call rate across all 22 behaviors of 0.34 calls per individual per minute for residents and 0.05 calls per individual per 
1 minute for transients. Call rates were reported to be highest for surface-active and post-feeding

2 behaviours of transients, but mostly null during all other behaviours.

3

4 Acoustic events containing Resident calls in the present study frequently included periods of

5 silence that lasted 3 to 4 samples (between 2 and 2.5 hours) before calls from the same dialect

6 were detected again. A larger number of samples without calls was rarely observed within these

7 events; when more than 4 samples didn't contain calls, the next sample with killer whale calls

8 was usually not encountered until much later, suggesting the probability of belonging to a

9 different group was higher.

11 Killer whale swim speed ranges between 3 and $10 \mathrm{~km} / \mathrm{h}$ and varies with behavioural state (Ford,

12 1989, Barrett-Lennard et al., 1996). Assuming an average audible radius of $10 \mathrm{~km}$ (estimations

13 of detection range are discussed further below) at the mostly noisy study site, and if the whales

14 travel on a straight trajectory, it is likely that they will clear the audible area in less than 3 hours.

15 Therefore, based on a 1/3 duty cycle, a limit of 6 samples without calls was used for Residents,

16 assuming both samples contain call types from the same dialect, and of 3 samples for Transients,

17 to account for the fact that they vocalize significantly less often than Residents. The time that

18 passes from the beginning until the end of an acoustic encounter is referred to as "encounter

19 duration” (Fig. 3).

20

\section{E. Comparing different methodological approaches}

22 To assess the efficiency of the $2 / 3$ duty cycle used for sampling, or to investigate what would be

23 an "ideal" duty cycle, the data from August 2009 were transformed to a 1/3 duty cycle, creating a 
1

7

new LTSA with half of the files, keeping the ones that started at 20 and 40 minutes after the hour. This creates an effective duty cycle as if the hydrophone had been recording 10-minute samples every 30 minutes (10 minutes on, 20 minutes off).

Both LTSAs corresponding to 2/3 and 1/3 duty cycles were analyzed using the LTSA with the technique described above. Then, to assess the efficiency of the LTSA tool, the data prepared with 1/3 duty cycle were analyzed in Real-Time.

The difference between using the averaged data in the LTSA and analyzing the data set in RealTime is the resolution of the spectral image that is being visualized. The LTSA uses a combination of spectral averages allowing one to skip uneventful portions of data, with occasional analysis of spectrograms to confirm detection or identify calls, whereas in Real-Time analysis every second of data is visualized as a spectrogram, including the portions of data not containing calls. In using the LTSA there could be a subjective error if the operator fails to see the pattern that corresponds to the target signal, but there is also an intrinsic error due to the smearing effect of the 5 second time average bin that could suppress some calls. In Real-Time analysis, the error is mainly subjective error if the operator fails to recognize a signal as belonging to killer whales.

\section{F. Detection range}

The sonar equation is used here to determine a minimal signal-to-noise ratio (SNR) with a signal excess (SE) or threshold above which a given signal will be detected (Zimmer, 2011). The signal excess can be estimated as the received signal level (RS) minus the noise level (NL). 


$$
S N R=S E=R S-N L
$$

2 In turn, the received signal can be calculated as the source level (SL) minus the transmission loss 3 (TL).

4

$$
R S=S L-T L
$$

5

6 Therefore, the signal-to-noise ratio $(\mathrm{dB})$ for passive acoustic monitoring of cetaceans can be 7 described as:

8

$$
S N R=S L-T L-N L
$$

9

10 For the shallow water coastal site, we use the simple three-halves law from Weston (1971):

11

$$
T L=15 \log R+5 \log H+5 \log b / 5.2+\alpha R,
$$

12

13 where $H$ is the water depth, $\alpha$ is the absorption of sound in sea water $(\mathrm{dB} / \mathrm{m})$ and $\mathrm{b}$ accounts for

14 bottom interaction loss (here $b=118.8$ ). To calculate the detection range (R) of the hydrophone

15 from the source of call, we assumed a signal-to-noise ratio of $5 \mathrm{~dB}$.

16 Broadband source levels for Northern Resident killer whale calls recorded off northeastern

17 Vancouver Island have been reported to range between 131 and $168 \mathrm{~dB}$ re $1 \mu \mathrm{Pa}$ (Miller, 2006).

18 The noise level in the band $1-20 \mathrm{kHz}$ consistent with Miller (2006) is estimated as $84 \mathrm{~dB}$ re 1

$19 \mu \mathrm{Pa}$ for sea state 2 conditions at sea. Equation 4 was solved numerically, using an absorption 
1

4

coefficient of $0.0002 \mathrm{~dB} / \mathrm{m}$ at $4 \mathrm{kHz}$. For the maximum SL of $168 \mathrm{~dB}$ re $1 \mu \mathrm{Pa}$, the detection range was $\sim 9.5 \mathrm{~km}$.

\section{RESULTS}

\section{A. Type of analysis: Real-Time vs. LTSA (for $1 / 3$ duty cycle)}

\section{Number of samples}

Intuitively, the Real-Time analysis was expected to detect more samples with killer whale calls than the LTSA analysis, due to the different spectral processing techniques used in each method. There were 154 acoustic samples containing killer whale calls in the 1/3 duty cycle dataset. Of these, 91 (59.1\%) were found with both Real-Time and LTSA analyses (Table I). The remaining 63 samples (40.9\%) were missed by the LTSA analysis. There was no sample detected exclusively with the LTSA analysis. These results support the expectation that the Real-Time analysis is likely to provide a more accurate number of samples with killer whale calls.

\section{Number of encounters}

Because some samples were missed by the LTSA, there is no reason to expect the same number of encounters for the Real-Time and LTSA analyses after applying the definition of "encounter". Missing samples doesn't necessarily have an impact on the final number of encounters. For example, missing one sample in the middle of a long encounter might not be relevant. But there can be cases in which missing samples creates new additional encounters, and sometimes cause an encounter to be completely missed. 
1 There were 28 encounters for the Real-Time analysis, and 27 encounters for the LTSA analysis.

2 Among the encounters in Real-Time, 23 (82\%) were the same in LTSA (Table I). The remaining

35 encounters determined from the Real-Time analysis were missed by the LTSA analysis, an

4 example of underestimation by LTSA. The remaining 4 encounters in LTSA are "false

5 positives”. They arise as a result of missing samples with the LTSA, which, after applying the

6 definition, leads to several shorter encounters that would have been one long encounter

7 otherwise. This is an example of overestimation by LTSA.

\section{3. Encounter duration}

10 Even when missing samples didn't impact the number of encounters, the encounter duration may

11 be affected, depending on which samples were missed. Sometimes samples were missed at the

12 beginning or end of an encounter, and therefore its duration was shorter in the LTSA analysis.

13 Figure 2 shows the number of times missing samples resulted in a different encounter duration,

14 using the total number of encounters of Real-Time as the more accurate number. There were 12

15 encounters with the same duration in both analyses, and 16 were different (either shorter in

16 LTSA, or absent).

17

18 If only the 23 encounters that were the same in both Real-Time and LTSA are considered, the 12

19 that had the same encounter duration would account for only $47.8 \%$.

20 Table I shows a qualitative comparison between both techniques: the number of times the

21 encounter duration was different due to missed samples. For a quantitative estimation of how

22 different the duration was between the two analyses, the average encounter duration was $4.4 \pm$

$23 \quad 3.5 \mathrm{~h}$ for Residents (median $3.4 \mathrm{~h}$ ) and $0.4 \pm 0.5 \mathrm{~h}$ for Transients (median $0.2 \mathrm{~h}$ ) for the Real- 
1 Time analysis, and $2.8 \pm 3.0 \mathrm{~h}$ for Residents (median $2.4 \mathrm{~h}$ ) and $0.7 \pm 0.7 \mathrm{~h}$ for Transients

2 (median $0.7 \mathrm{~h}$ ) for the LTSA analysis.

\section{4. Encounter identification}

5 Of the 28 encounters in Real-Time, 23 had positive ID (82.1\%), and 5 were Unidentified killer

6 whales (17.9\%) due to the calls being too faint (Fig. 4). Of the 27 encounters in LTSA, 19 had

7 positive ID (70.4\%), and 8 were Unidentified killer whales (29.6\%). Of these ones, 5 were due to

8 missing samples (17.9\%). The remaining 3 unidentified encounters in LTSA were due to faint

9 calls and correspond to the same ones in Real-Time. The 2 remaining unidentified encounters

10 due to faint calls in Real-Time were totally missed in the LTSA. Of the 5 unidentified encounters

11 due to missed samples in LTSA, 4 are "false positive" encounters. The remaining unidentified

12 encounter did have an equivalent encounter in Real-Time, but the sample containing identifiable

13 calls was missed by LTSA.

14

15 In other words, without missing any samples with killer whale calls, there are 5 cases with ID

16 problems in the Real-Time analysis. There are 8 cases with ID problems in the LTSA analysis, 5

17 of which are new unidentified encounters. So, missing samples leads to more ID problems.

\section{B. Duty cycle: $2 / 3$ vs. 1/3 (with LTSA)}

\section{Number of samples}

21 There were 201 acoustic samples containing killer whale calls for the 2/3 duty cycle and 91 for

22 the $1 / 3$ duty cycle. Adding the number of samples that were common (86) and exclusive to both 
1 (115+5), a total of 206 samples with calls were detected with the LTSA analysis (Table II). The

2 proportion of samples that were found in both $2 / 3$ and $1 / 3$ duty cycles was $41.7 \%$. The lower

3 duty cycle missed $55.8 \%$ of samples with calls (71 of these (62\%) were not available on this duty

4 cycle because they were removed in creating the duty cycle, the remaining 44 samples (38\%)

5 were simply not detected), and $2.4 \%$ of the samples were only detected on the $1 / 3$ dataset

6 (missed on the longer duty cycle).

7

8 Since no Real-Time analysis was performed on the 2/3 duty cycle data, the total number of

9 samples with killer whale calls is likely less accurate, and therefore the number of missed

10 samples might actually be larger than 5 .

11

\section{2. Number of encounters}

13 There were 29 encounters in the 2/3 duty cycle and 27 encounters in the $1 / 3$ duty cycle (Table I).

14 Considering that half of the samples were removed to create the $1 / 3$ duty cycle, the total number

15 of encounters in both is still close. So at first sight reducing the duty cycle didn't cause a

16 significant loss in terms of number of encounters. However, the LTSA misses samples, and even

17 though the total number of encounters in both duty cycles looks similar, some of them are "false

18 positives". In fact, the number of "false positives" may be higher than what was found, but this

19 can't be quantified exactly because no Real-Time analysis was performed on the 2/3 duty cycle 20 data.

21

22 Looking in more detail (Fig. 5), 22 encounters were matching in both duty cycles. Of the 7

23 encounters that were exclusive to 2/3 (Fig. 5 top), 6 were missed in the 1/3 duty cycle because 
1 the samples were removed. These were one-sample encounters of BC Transients (5) or

2 "Unidentified" encounters (1). The latter are generally characterized by low-quality faint, distant

3 or masked calls. The remaining encounter exclusive to $2 / 3$ could have been missed because it

4 contained faint calls, which are more difficult to detect on the LTSA.

5

6 There were 5 encounters exclusive to the $1 / 3$ duty cycle (Fig. 5 bottom). Of these, 1 encounter

7 corresponds to a one-sample unidentified encounter that was detected in 1/3 but missed in 2/3.

8 That could, again, be due to the errors associated with LTSA analysis. The remaining 4

9 encounters were "false positives" resulting from applying the definition after missing samples,

10 which meant that a long unique encounter in $2 / 3$ was perceived as several shorter encounters in

$11 \quad 1 / 3$.

12

\section{Encounter duration}

14 The effect of different duty cycles on encounter duration was assessed by comparing both sets

15 (Table II), assuming the more accurate (closer to reality) number of encounters is the one

16 obtained for the $2 / 3$ duty cycle. However, the one encounter that was detected in $1 / 3$ but missed

17 in 2/3 was also included in the comparison, so the total number of encounters considered for

18 encounter duration was 30. Unlike the previous section, the LTSA was used on both duty cycles.

19 Thus, samples could be missed in either one of the duty cycles, resulting in some encounters

20 being longer for the $2 / 3$ duty cycle and some being longer for the $1 / 3$ duty cycle.

21 There were 7 encounters with the same duration in both duty cycles. Of the 23 encounters that

22 had different duration, 4 were longer in $1 / 3$, due to the LTSA missing samples in 2/3 (that

23 includes the encounter that was missed in 2/3). The remaining 19 encounters were longer in 2/3 
1 due to samples missed in the $1 / 3$ duty cycle. Of these, 16 were due to the removed samples, 1

2 was due to missed samples, and 2 were due to both removed and missed samples.

3

4 If we consider only the 22 matching encounters between the $2 / 3$ and $1 / 3$ duty cycles, the 7 that

5 had the same encounter duration would account for 31.8\%. Thus, only about a third of them had

6 the same duration.

7

8 For a quantitative estimation of how different the duration was between the two duty cycles, the

9 average encounter duration was $4.0 \pm 2.8 \mathrm{~h}$ for Residents (median $3.4 \mathrm{~h}$ ) and $0.4 \pm 0.4 \mathrm{~h}$ for

10 Transients (median $0.2 \mathrm{~h}$ ) for the 2/3 duty cycle and $2.8 \pm 3.0 \mathrm{~h}$ for Residents (median $2.4 \mathrm{~h}$ ) and

$11 \quad 0.7 \pm 0.7 \mathrm{~h}$ for Transients (median $0.7 \mathrm{~h}$ ) for the $1 / 3$ duty cycle.

12

\section{Encounter identification}

14 Of the 29 encounters in the 2/3 duty cycle, 26 had positive ID (89.7\%), and 3 were Unidentified 15 killer whales (10.3\%) due to the calls being too faint (Fig. 6). Of the 27 encounters in the 1/3 16 duty cycle, 19 had positive ID (70.4\%), and 8 were Unidentified killer whales (29.6\%). Of these,

173 were due to faint calls and 5 were due to missing samples (18.5\%), either due to the analysis

18 technique or because they were artificially removed to create the $1 / 3$ duty cycle. Of the 3

19 "unidentified due to faint calls" in the 1/3 duty cycle, 2 are the same as the ones in the 2/3 duty

20 cycle. The remaining one corresponds to the one encounter that was missed in the 2/3 duty cycle

21 (a 10-minute encounter). The third unidentified encounter due to faint calls on 2/3 was missed on

22 the $1 / 3$ duty cycle because it was also a 10-minute encounter and that sample was removed. 
1 Of the 5 unidentified ID due to missed samples on 1/3 duty cycle, 3 are "false positive"

2 encounters. All 5 of these had ID problems, both due to samples being removed and missing

3 samples. The remaining 2 unidentified encounters did have an equivalent encounter in $2 / 3$, but

4 the sample containing identifiable calls was missed in $1 / 3$.

5

6 Unlike the first comparison of this section (RT vs. LTSA), in this case both analyses were done

7 using the LTSA. We know quantitatively what was missed on the $1 / 3$ duty cycle, but no Real-

8 Time analysis was performed on the 2/3 duty cycle data. Therefore, it is very likely that more

9 samples with killer whale calls have been missed. The number of unidentified encounters could

10 be lower than 3 (or the number of positive ID could be higher).

\section{IV. DISCUSSION}

\section{A. Types of analysis}

14 Since the use of LTSAs to search for killer whale calls impliesa partial analysis where only

15 selected sections of data are examined in depth, it is natural to expect that it will result in fewer

16 detections than analysis in Real-Time which involves a detailed inspection of every file. This

17 effect can be broken down into four consequences based on the results of this study. First, the

18 number of detections was different for each method; $41 \%$ of the 10 -minute acoustic samples

19 containing killer whale calls were missed with the LTSA method (Table I). For any given study,

20 the impact of such a low success rate will depend on the objectives. For example, high levels of

21 precision are not necessary to estimate the relative frequency of killer whale visits to the area in

22 terms of presence per day or per month. Rayment et al. (2011) used T-PODS, commercially

23 available acoustic data loggers, to investigate Maui’s dolphin habitat use in New Zealand. To 
1 determine their presence they used the number of detections per monitoring day as a compromise

2 between temporal resolution and independence of the data points. Yurk et al. (2010) determined

3 the presence of identified killer whale pods as number of daily occurrences for each month.

4 However, the importance of potential habitat for a given species is likely correlated with the

5 amount of time individuals spend in it, an estimate of which may only be appreciable with a

6 higher temporal resolution of detections (for example, detections per hour). Therefore, low

7 detection rates due to limitations of the analyzing tool may result in poor representation of

8 habitat use. In contrast, a higher monitoring effort and more detailed analysis may provide

9 valuable information and lead to important discoveries. For example, a 20-day acoustic pilot

10 study in the Bering Sea involved the visual and aural analysis of every 15-minute sample and

11 showed a constant presence of Transient killer whales, thus identifying a predation hot spot

12 (Newman and Springer, 2008).

14 In this study, importance was given to identifying the significance (and use) of the area by killer

15 whales, which required extracting information from the data to the maximum possible detail. For

16 this reason killer whale detections were organized into acoustic encounters, as defined in

17 previous sections. Thus, the second consequence of a different success rate between analysis

18 methods is an effect on the number of encounters, $18 \%$ of which were exclusive to the Real-

19 Time analysis (Table I). However, there is no guarantee that the number of encounters that were

20 in common between both techniques was equivalent. For instance, missing samples containing

21 killer whale calls sometimes resulted in the creation of false positives. The present results

22 suggest that the number of encounters is less reliable when obtained from the LTSA analysis as

23 opposed to Real-Time. Noteworthy is the fact that missing samples with calls didn't have any 
1 effect on number of encounters when these samples were less than 3 hours apart from other

2 Resident calls or less than 1.5 hours apart from other Transient calls. Since a killer whale

3 acoustic encounter is an artificial concept, it is not recommended by itself as a measure of killer

4 whale visits because it is not possible to determine whether the individuals that are detected are

5 the same or different from previous encounters.

6

7 Encounters are generated in order to quantify killer whale presence, and from them a more

8 biologically significant parameter is obtained: the amount of time the whales spend on site.

9 Differences in encounter duration are the third consequence of missing samples. Studies of

10 critical habitat, assessment of human impact or identification of areas requiring protection are

11 likely to benefit from such a time measurement parameter, as it indicates how important the area

12 is for the studied species. Little evidence of time spent on site could indicate low use of the area,

13 although absence of detection does not prove absence of whales, as they could be silent. In

14 contrast, evidence of frequent presence likely indicates a use of the habitat for important life

15 functions and behaviours, some as essential as feeding. According to the requirements to define

16 critical habitat (Ford, 2006), identifying feeding grounds is one of the top priorities. Therefore, a

17 parameter that allows assessment of the amount of time the whales spend on site is highly

18 relevant for conservation purposes. Ideally, the exact amount of time the whales are present

19 should be obtained and used as an indication of habitat significance. But with PAM only, this is

20 not possible. Here, the encounter duration was tested as a parameter to assess how important

21 Swiftsure Bank is for different ecotypes of killer whales. The impact of using different

22 methodologies was that the encounter duration was different for $57 \%$ of the encounters (Table I).

23 Quantitatively, the median encounter duration for Residents was 3.4 hours with Real-Time 
compared to 2.4 hours with LTSA. These show that the encounter duration can be underestimated when using the LTSA technique. Thus, an analysis in Real-Time would be more suited than LTSA for studies that intend to assess habitat use quantitatively with PAM.

Finally, the fourth outcome of detecting fewer calls is an effect on the identification of the killer whale groups that are found. Ideally, each encounter would correspond to a known killer whale pod, positively identified from their distinctive dialects (Ford, 1989). Due to the limitations of PAM, it is actually not possible to reach the desired precision of identification for many encounters. The level of identification resolution depends on the quality and clarity of calls, and ranges from pod to community and ecotype. When calls were so faint that they were barely identified as belonging to killer whales, they were assigned to an "unidentified killer whale" category. Figure 4 shows that there are more unidentified killer whale encounters when using the LTSA method, due to missing samples that contain calls necessary for a positive identification. Knowing what groups of killer whales use the area is important to assess the need to protect it. Not all killer whale ecotypes that share these waters are listed under the same degree of risk. For instance, the Southern Resident population is the only one that is Endangered (COSEWIC, 2008). However, the other populations are listed as Threatened, so all populations should be taken into account when assessing importance of habitat, especially when they share it. Also, if killer whales are detected but are not identified in higher resolution, the use of such information is more limited. Therefore, a higher degree of precision in group identification is recommended in order to estimate whether and how the area needs to be managed. 
1 It must be noted that although LTSAs can be used to analyze different types of acoustic datasets,

2 they were originally designed to process acoustic data collected by HARPs (Wiggins and

3 Hildebrand, 2007), which have a significantly higher sampling rate than the AURALs used here

$4 \quad$ (200 kHz as opposed to $32 \mathrm{kHz}$, respectively) and therefore displays more information that helps

5 detecting killer whale vocalizations. The primary energy of killer whale pulsed calls ranges

6 between 1 and $6 \mathrm{kHz}$, but can extend to frequencies higher than $30 \mathrm{kHz}$ (Ford, 1987). In

7 addition, broadband echolocation clicksmight provide an additional clear visual cue indicating

8 the presence of odontocetes that could be killer whales. The contrast between both target signals

9 (pulsed calls and echolocation clicks) and other non-significant signals is greater on an LTSA

10 that can display frequencies up to $100 \mathrm{kHz}$ compared to one that only extends to $8 \mathrm{kHz}$, and the

11 patterns are therefore more likely to be recognized. Therefore, having the option to visually

12 examine the data above such frequencies could perhaps simplify the task of searching for killer

13 whale calls using the LTSA and might be a reason why this method was not as effective as

14 expected for the data collected at Swiftsure Bank. The fact that noise levels due to passing ships

15 were high in Swiftsure Bank may also have an effect on the performance of the LTSA by

16 distorting the spectral averaging at the already mentioned low frequency ranges.

18 Complementing acoustic data with other forms of data would certainly improve estimates of time

19 the whales spend in the area. Kyhn et al. (2012) tested the robustness of their PAM system to

20 obtain density of harbour porpoises (Phocoena phocoena) by comparing acoustic detections with

21 simultaneous visual detections, in the form of a mark-recapture system. The use of infrared

22 imagery includes the addition of night-time killer whale detections as opposed to visual

23 observations, and can also be analyzed automatically (Graber et al., 2011). Different passive 
1 acoustic instruments can also be combined to maximize detection rate, when two methods are

2 best suited for a certain type of vocalization. For example EARs (ecological acoustic recorders),

3 are more efficient at recording distant faint beluga (Delphinapterus leucas) calls, whereas

4 echolocation clicks are more reliably detected by automatic echolocation click detectors

5 (Lammers et al., 2012).

6

\section{B. Effect of duty cycle}

8 Defining the most effective duty cycle for a given study depends on issues such as battery

9 capacity, availability of ship time to deploy and recover instruments, hydrophone sampling rate

10 and sensitivity, disk storage capacity, target species and the characteristics of their vocal

11 behaviour (how often they vocalize), and the objectives of the study (how much detail is needed

12 in the information that is to be gathered). Selecting an appropriate duty cycle for killer whales

13 has to account for the fact that they are not constantly vocalizing, and for the significant

14 differences in call rates between the different ecotypes (Ford, 1989, Deecke et al., 2005). Here, 15 two duty cycles were tested: $1 / 3$ and $2 / 3$, to assess the impact of using a higher or lower duty 16 cycle.

17

18 The number of samples containing detected calls is expected to be greater for the higher duty

19 cycle. However, the proportion of samples containing calls in this study was larger in the samples exclusive to the higher duty cycle than in the ones that were also available on the lower

21 duty cycle (Table II), suggesting that reducing the amount of samples by half does not

22 necessarily mean a proportional loss of detections. Also, a small percentage of samples

23 containing calls was only detected on the lower duty cycle. This is due to the fact that both 
datasets were analyzed using the LTSA tool, and can be explained by the error that is associated with this technique. Since the 2/3 duty cycle data were not analyzed in Real-Time, the total number of samples containing calls is not known, and therefore the number of samples with calls that were missed may be larger than what is reported, for both data sets.

The impact of missing samples may not always affect the results, depending on the objectives. In this study, reducing the duty cycle resulted in $24 \%$ of encounters being missed (Fig. 5), due to the samples being absent on the 1/3 dataset combined with the limitations of the LTSA technique. Transients are less vocal than Residents, and sometimes their calls were only detected on a single sample. Reducing the duty cycle increased the likelihood of missing short Transient encounters. It also increased the number of false positives.

Encounter duration was highly affected by the reduction in duty cycle. Only $23 \%$ of encounters had the same duration (Table II). More encounters were expected to have a longer encounter duration on the 2/3 dataset, as it contains more samples. However, some encounters had a longer duration on the lower duty cycle, due to the errors associated with the LTSA technique. Quantitatively, median encounter duration for Residents was 3.4 hours on the 2/3 duty cycle and 2.4 hours on the $1 / 3$ duty cycle. The median encounter duration for Transients was 0.2 compared to 0.7 hours between higher and lower duty cycles, respectively. The reason why it was shorter on the higher duty cycle is that short 10-minute encounters were detected on this dataset, but only longer encounters were found on the other dataset. Figure 6 shows that the rate of success of encounter identification was higher on the $2 / 3$ duty cycle ( $90 \%$ encounters with positive ID) than on the $1 / 3$ duty cycle ( $70 \%$ had positive ID). This suggests that halving the duty cycle also 
1

2 identification success).

3

4 The ideal duty cycle for PAM of killer whales depends largely on the objective of the study: how

5 much detail is needed. For a relative estimate of presence and a general sense of seasonality, a

6 lower duty cycle might be sufficient. Yurk et al. (2010) listened to sounds being broadcast from

7 the sampling site opportunistically, and recorded only when killer whale calls were detected. But

8 a higher duty cycle is more recommendable for a detailed account of presence, a more realistic

9 measure of time present, and a higher rate of identification success. Newman \& Springer (2008)

10 recorded continuously for 20 days, thus obtaining complete time coverage over a short period of

11 time.

12

13 Performing a Real-Time analysis on the 2/3 duty cycle would allow evaluation of the exact

14 number of samples that were missed on both duty cycles and enable a more precise estimate of

15 the effects of a reduced duty cycle. Analyzing acoustic samples that were collected with a 100\%

16 duty cycle, in Real-Time, would certainly maximise the precision of such assessment by

17 providing an absolute reference number of calls that are missed when using lower duty cycles.

\section{Limitations}

20 With PAM a lack of detection does not necessarily indicate absence of killer whales because

21 they could be silent. Also, the calls they produce are directional at high frequencies. The

22 frequency structure depends on the orientation of the calling whale, and the high-frequency

23 components are attenuated when the signaler is oriented away from the hydrophone (Miller 
1 2000). Therefore, the calls with high frequency components will only be detected if they are

2 facing the hydrophone when they produce calls. In addition, given that some call types contain

3 high frequency components whereas others only contain low frequency components (Yurk

4 2002), some call types will be more likely to be detected by the hydrophone than others. This

5 makes their detection opportunistic and relying on the episodes when they do vocalize,

6 producing calls with low frequency components, and with body orientation towards the

7 hydrophone. Some studies reported different calling rates depending on behaviour (Ford, 1989,

8 Deecke et al., 2005) but little is known about the vocalization rate of individual killer whales,

9 nor if it is affected by circadian rhythms. PAM of killer whales has been used to investigate their

10 vocal behaviour at night (Newman and Springer, 2008). Suction-cup attached dataloggers (D-

11 tags; Johnson and Tyack, 2003) could also provide some insights into these patterns. D-tags have

12 been used to investigate individual call rates of North Atlantic right whales (Eubalaena glacialis)

13 in different contexts to assess the potential for passive acoustic detection of this endangered

14 species (Parks et al., 2011). Quantitative studies on the rate of vocalization of different ecotypes

15 of killer whales in the context of time would provide valuable information to assess the

16 likelihood of silent whales being present around the hydrophone on a daily basis. In the absence

17 of such knowledge, this study makes the assumption that absence of call detection is correlated

18 with absence of whales. The results are therefore likely to be an underestimation of killer whale 19 presence.

20

21 One of the advantages of conducting this study in cool temperate waters of the coastal

22 northeastern Pacific is that killer whales are the only odontocete that produce stereotyped pulsed

23 calls with primary energy ranging between 1 and $6 \mathrm{kHz}$ (Ford, 1987). This eliminates the risk of 
1 confusing their calls with some other toothed whale's with similar characteristics, such as pilot

2 whales (Globicephala sp.). Other oceanic regions of the world (e.g. Norway, Eskesen et al.,

3 2011) are inhabited by both species, presenting a challenge for PAM of killer whales in these

4 areas. Eskesen et al. (2011) found differences in duration, energy and frequency of killer whale

5 and pilot whale clicks that could allow distinguishing both species when using automated

6 detection methods. Despite the absence of pilot whales in British Columbia waters, some

7 confusion about the identity of a detected vocalization occasionally happened with humpback

8 whale calls. These are usually low-frequency, but some units of their songs appear similar to

9 killer whale pulsed calls, as their harmonics reach frequencies as high as $24 \mathrm{kHz}$ (Au et al.,

10 2006). The confirmation of species identity was challenging when the calls were distant and

11 faint, but was usually more straightforward when the calls were clear and close to the

12 hydrophone.

14 Humpback whales do, however, present a more serious challenge to the detection of killer whale

15 calls due to masking, especially in August and September. These months correspond to

16 humpback whale feeding season (Darling and McSweeney, 1985, Calambokidis et al., 2001),

17 and their vocalizations were loud and frequent, often masking faint and distant killer whale calls.

18 Masking also occurs due to powered vessels, which are very frequent in Swiftsure Bank.

19 Complete masking, where noise levels were above $105 \mathrm{~dB}$ re $1 \mu \mathrm{Pa}$ at $2 \mathrm{kHz}$ and the boat signal

20 overpowered any other kind of signal, occurred on $22 \%$ of samples for the $1 / 3$ duty cycle data.

21 Other potential sources of masking noise are strong currents, storms and earthquakes. 
1 The hydrophone detection range in this study was estimated at $9.5 \mathrm{~km}$ for the maximum killer

2 whale call source levels and background noise. For noise levels greater than sea state 2 the

3 detection range would be considerably reduced. However, killer whales have been reported to

4 increase call amplitude and source levels in response to high ambient noise (Holt et al., 2009,

5 Holt et al., 2011). The estimated range over which calls were detected here are comparable to

6 other studies. Newman \& Springer (2008) reported detecting killer whales in the Pribilof Islands

7 at ranges of up to $4.5 \mathrm{~km}$ and Miller (2000) detected them off Vancouver Island over ranges of

84.5 to $26.2 \mathrm{~km}$. Communication signals from other species in noisy habitats have been detected

9 at shorter distances. Jensen et al. (2012) reported detection ranges smaller than $3 \mathrm{~km}$ for dolphin

10 whistles. However, whistle frequencies are higher than pulsed calls, and therefore are attenuated

11 at relatively shorter ranges. In addition, unlike killer whales, the dolphins did not increase source

12 levels to compensate for the high background noise (Jensen et al., 2012). In contrast, the low-

13 frequency calls of baleen whales can be detected over hundreds (Sirovic et al., 2007) or even

14 thousands of kilometres (Clark, 1995). Therefore, PAM of mysticetes can cover ocean basins

15 (Sirovic et al., 2004) whereas the detection of odontocete calls in shallow water is limited to a

16 much smaller spatial scale and would require a large network of autonomous recorders to

17 monitor extended areas. Lammers et al. (2012) used a network of 10 autonomous recorders to

18 monitor beluga seasonal occurrence and temporal and spatial patterns of habitat preference in

19 Cook Inlet, Alaska. A network of AURALs would certainly expand the area monitored for killer

20 whales and provide more information on their movements within this habitat.

21

22 Finally, the duty cycle adds to all other limitations because by definition it implies missing data.

23 D. Conclusion 
1 Both analysis methods and both duty cycles provided useful and valuable information about

2 killer whale occurrence that could potentially be applied to conservation and management

3 efforts. However, each has proven to possess different advantages and limitations that increase

4 their efficiency when used for different goals. Real-Time analysis may be more suited for

5 extensive, detailed assessments of habitat use and conservation, or for more advanced stages of

6 such specific studies. LTSA is a valuable tool for obtaining a general overview of presence or

7 absence of killer whales in a given area, with a less time-consuming analysis.

9 The present study has shown that a low duty cycle combined with LTSA causes not only some

10 samples but also entire encounters to be missed, more false positive encounters, underestimations

11 of encounter length and a lower success rate for pod identification. Therefore, in order to

12 maximize the efficiency of detections within the available data, increasing the duty cycle would

13 be recommended for analysis intended to use LTSA. On the other hand, a lower duty cycle may

14 still provide sufficient information from data analyzed in Real-Time.

16 Further studies are needed, for example combining acoustic with visual methods, tagging whales,

17 analyzing a recording in Real-Time of a $100 \%$ duty cycle, or even testing the same methodology

18 at a different location, perhaps less noisy. These would provide additional clues to improve the

19 efficiency of studies conducting PAM of killer whales.

\section{ACKNOWLEDGEMENTS}

22 The authors would like to thank John Hildebrand and Sean Wiggins for providing the software

23 Triton that was used in this study and for their help in providing training on using the software 
1 and tools. Thanks to Robin Abernethy for extracting the sound files from the instrument and

2 handling the data before analysis. We would also like to acknowledge Tamas Juhasz and

3 colleagues for conducting the deployment and recovery of the AURAL on Swiftsure Bank. This

4 study was supported by Obra Social La Caixa and the International Council for Canadian Studies

5 and the Species at Risk program of Fisheries and Oceans Canada.

6

7 REFERENCES

8 Au, W. W. L., Pack, A. A., Lammers, M. O., Herman, L. M., Deakos, M. H., Andrews, K. (2006). "Acoustic properties of humpback whale songs", J. Acoust. Soc. Am. 120, 11031110.

Baird, R. W. (2001). "Status of Killer Whales, Orcinus orca, in Canada", Can. Field-Nat. 115, 676-701.

Barrett-Lennard, L. G., Ford, J. K. B., Heise, K. A. (1996). "The mixed blessing of echolocation: differences in sonar use by fish-eating and mammal-eating killer whales", Anim. Behav. 51, 553-565.

Bigg, M. A., Olesiuk, P. F., Ellis, G. M., Ford, J. K. B., Balcomb III, K. C. (1990). "Social organization and genealogy of resident killer whales (Orcinus orca) in the coastal waters of British Columbia and Washington State", Rep. Int. Whal. Commn. Special Issue 12, 383-405.

Brown, J. C., Miller, P. J. O. (2007). "Automatic classification of killer whale vocalizations using dynamic time warping", J. Acoust. Soc. Am. 122, 1201-1207. 
1 Calambokidis, J., Steiger, G. H., Straley, J. M., Herman, L. M. and others (2001). "Movements and population structure of humpback whales in the North Pacific", Mar. Mamm. Sci. 17, 769-794.

Clark, C. W. (1995). "Matters arising out of the discussion of blue whales", Rep. Int. Whal. Commn 45, 210-212.

COSEWIC (2008). "COSEWIC assessment and update status report on the killer whale Orcinus orca, Southern Resident population, Northern Resident population, West Coast Transient population, Offshore population and Northwest Atlantic / Eastern Arctic population, in Canada", Committee on the Status of Endangered Wildlife in Canada, Ottawa, viii + 65 pp.

Dahlheim, M. E., Schulman-Janiger, A., Black, N., Ternullo, R., Ellifrit, D., Balcomb, K. C., II (2008). "Eastern temperate North Pacific offshore killer whales (Orcinus orca): Occurrence, movements, and insights into feeding ecology", Mar. Mamm. Sci. 24, 719729.

Darling, J. D., McSweeney, D. J. (1985). "Observations on the migrations of North Pacific humpback whales (Megaptera novaeangliae)", Can. J. Zool. 63, 308-314.

Deecke, V. B., Ford, J. K. B., Slater, P. J. B. (2005). "The vocal behaviour of mammal-eating killer whales: communicating with costly calls", Anim. Behav. 69, 395-405.

Eskesen, I. G., Wahlberg, M., Simon, M., Larsen, O. N. (2011). "Comparison of echolocation clicks from geographically sympatric killer whales and long-finned pilot whales", J. Acoust. Soc. Am. 130, 9-12. 
Fisheries and Oceans Canada (2005). "Fishing within Swiftsure Bank closed area leads to fine". Accessed on: March 6, 2012. Available from: http://www.dfo-mpo.gc.ca/media/npresscommunique/2005/pr69-eng.htm

Ford, J. K. B. (1987). "A catalogue of underwater calls produced by killer whales (Orcinus orca) in British Columbia", Can. Data Rep. Fish. Aquat. Sci. 633, 165 p.

Ford, J. K. B. (1989). "Acoustic behaviour of resident killer whales (Orcinus orca) off Vancouver Island, British Columbia", Can. J. Zool. 67, 727-745.

Ford, J. K. B. (1991). "Vocal traditions among resident killer whales (Orcinus orca) in coastal waters of British Columbia", Can. J. Zool. 69, 1454-1483.

Ford, J. K. B. (2006). "An assessment of critical habitats of resident killer whales in waters off the Pacific coast of Canada". Report No. 2006/072, Canadian Science Advisory Secretariat, Fisheries \& Oceans Canada, Nanaimo, BC, iv + 34 pp.

Ford, J. K. B., Ellis, G. M., Barrett-Lennard, L. G., Morton, A. B., Palm, R. S., Balcomb III, K. C. (1998). "Dietary specialization in two sympatric populations of killer whales (Orcinus orca) in coastal British Columbia and adjacent waters", Can. J. Zool. 76, 1456-1471.

Ford, J. K. B., Ellis, G. M., Matkin, C. O., Wetklo, M. H., Barrett-Lennard, L. G., Withler, R. E. (2011). "Shark predation and tooth wear in a population of northeastern Pacific killer whales", Aquat. Biol. 11, 213-224.

Graber, J., Thomson, J., Polagye, B., Jessup, A. (2011). "Land-based infrared imagery for marine mammal detection," in: Remote Sensing and Modeling of Ecosystems for Sustainability Viii, Vol. 8156 
Hoelzel, A. R., Dahlheim, M., Stern, S. J. (1998). "Low genetic variation among killer whales (Orcinus orca) in the eastern North Pacific and genetic differentiation between foraging specialists", J. Hered. 89, 121-128.

Holt, M. M., Noren, D. P., Emmons, C. K. (2011). "Effects of noise levels and call types on the source levels of killer whale calls", J. Acoust. Soc. Am. 130, 3100-3106.

Holt, M. M., Noren, D. P., Veirs, V., Emmons, C. K., Veirs, S. (2009). "Speaking up: Killer whales (Orcinus orca) increase their call amplitude in response to vessel noise", J. Acoust. Soc. Am. 125, EL27-EL32.

Jensen, F. H., Beedholm, K., Wahlberg, M., Bejder, L., Madsen, P. T. (2012). "Estimated communication range and energetic cost of bottlenose dolphin whistles in a tropical habitat", J. Acoust. Soc. Am. 131, 582-592.

Johnson, M. P., Tyack, P. L. (2003). "A digital acoustic recording tag for measuring the response of wild marine mammals to sound", IEEE J. Ocean. Eng. 28, 3-12.

Kyhn, L. A., Tougaard, J., Thomas, L., Duve, L. R. and others (2012). "From echolocation clicks to animal density---Acoustic sampling of harbor porpoises with static dataloggers", J. Acoust. Soc. Am. 131, 550-560.

Lammers, M. O., Small, R., Atkinson, S., Castellote, M. and others (2012). "Acoustic monitoring of Beluga whales (Delphinapterus leucas) in Cook Inlet, Alaska", Adv. Exp. Med. Biol. 730, 341-344.

Matzner, S., Fu, T., Ren, H., Deng, Z. D., Sun, Y., Carlson, T. (2011). "Operational performance analysis of passive acoustic monitoring for killer whales," in: Oceans 2011, Vol.,(IEEE 
Miller, P. J. O. (2000). "Maintaining contact: design and use of acoustic signals in killer whales, Orcinus orca". Ph.D. thesis, Woods Hole Oceanographic Institution and Massachusetts Institute of Technology.

Miller, P. J. O. (2006). "Diversity in sound pressure levels and estimated active space of resident killer whale vocalizations", J. Comp. Physiol. A 192, 449-459.

Morin, P. A., Archer, F. I., Foote, A. D., Vilstrup, J. and others (2010). "Complete mitochondrial genome phylogeographic analysis of killer whales (Orcinus orca) indicates multiple species", Genome Res. 20, 908-916.

Multi-Électronnique (MTE) Inc. (2012) "Aural-M2 design". Accessed on: February 2, 2012. Available from: http://www.multi-electronique.com/pages/auralm2en.htm.

Newman, K., Springer, A. M. (2008). "Nocturnal activity by mammal-eating killer whales at a predation hot spot in the Bering Sea", Mar. Mamm. Sci. 24, 990-999.

Oleson, E. M., Calambokidis, J., Falcone, E., Schorr, G., Hildebrand, J. A. (2009). "Acoustic and visual monitoring for cetaceans along the outer Washington coast", UCSD Scripps Institution of Oceanography, Cascadia Research Collective, Monterey, CA, 45.

Oswald, J. N., Rankin, S., Barlow, J. (2004). "The effect of recording and analysis bandwidth on acoustic identification of delphinid species", J. Acoust. Soc. Am. 116, 3178-3185.

Parks, S., Searby, A., Célérier, A., Johnson, M., Nowacek, D., Tyack, P. (2011). "Sound production behavior of individual North Atlantic right whales: implications for passive acoustic monitoring", Endang. Species Res. 15, 63-76.

Rayment, W., Dawson, S., Scali, S., Slooten, L. (2011). "Listening for a needle in a haystack: passive acoustic detection of dolphins at very low densities", Endang. Species Res. 14, $149-156$. 
Sirovic, A., Hildebrand, J. A. (2011). "Using passive acoustics to model blue whale habitat off the Western Antarctic Peninsula", Deep-Sea Res. Part II 58, 1719-1728.

Sirovic, A., Hildebrand, J. A., Wiggins, S. M. (2007). "Blue and fin whale call source levels and propagation range in the Southern Ocean", J. Acoust. Soc. Am. 122, 1208-1215.

Sirovic, A., Hildebrand, J. A., Wiggins, S. M., McDonald, M. A., Moore, S. E., Thiele, D. (2004). "Seasonality of blue and fin whale calls and the influence of sea ice in the Western Antarctic Peninsula", Deep-Sea Res. Part II 51, 2327-2344.

Weston, D. E. (1971). "Intensity-range relations in oceanographic acoustics", J. Sound Vib. 18, 271-287.

Wiggins, S. M., Hildebrand, J. A. (2007). "High-frequency Acoustic Recording Package (HARP) for broad-band, long-term marine mammal monitoring," in: 5th International Symposium on Underwater Technology and 5th Workshop on Scientific Use of Submarine Cables and Related Technologies, Vol.,(Institute of Electrical and Electronics Engeneers Ocean Engn Soc, Tokyo, Japan), 551-557.

Yurk, H., Filatova, O., Matkin, C. O., Barrett-Lennard, L. G., Brittain, M. (2010). "Sequential Habitat Use by Two Resident Killer Whale (Orcinus orca) Clans in Resurrection Bay, Alaska, as Determined by Remote Acoustic Monitoring", Aquat. Mamm. 36, 67-78.

Zimmer, W. M. X. (2011). Passive acoustic monitoring of cetaceans. (Cambridge University Press, Cambridge, UK), 356 pp. 
1 TABLE I. Comparison between Real-Time and LTSA analysis performed on the 1/3 duty cycle

2 in number and corresponding percentage: 10-minute acoustic samples containing killer whale

3 calls for each type of analysis; killer whale encounters that were found with each type of

4 analysis; and encounters found with the Real-Time analysis that had the same or different

5 duration than their corresponding encounters found with the LTSA analysis.

\begin{tabular}{|c|c|c|c|}
\hline \multicolumn{2}{|l|}{ Type of analysis (for $1 / 3$ duty cycle) } & Real-Time & LTSA \\
\hline Number of samples in dataset & Total & \multicolumn{2}{|c|}{1488} \\
\hline \multirow{3}{*}{$\begin{array}{l}\text { Number of samples containing killer } \\
\text { whale calls }\end{array}$} & Total & \multicolumn{2}{|c|}{154} \\
\hline & Exclusive & $63(41 \%)$ & 0 \\
\hline & Common & \multicolumn{2}{|c|}{$91(59 \%)$} \\
\hline \multirow{3}{*}{ Number of encounters } & Total & \multicolumn{2}{|c|}{32} \\
\hline & Exclusive & $5(16 \%)$ & $4(12 \%)$ \\
\hline & Common & \multicolumn{2}{|c|}{$23(72 \%)$} \\
\hline \multirow{3}{*}{ Encounter duration } & Total & \multicolumn{2}{|c|}{28} \\
\hline & Same & \multicolumn{2}{|c|}{$12(43 \%)$} \\
\hline & Different & \multicolumn{2}{|c|}{$16(57 \%)$} \\
\hline
\end{tabular}

6 
1 TABLE II. Comparison between 1/3 and 2/3 duty cycles analyzed with LTSA in number and

2 corresponding percentage: 10-minute acoustic samples containing killer whale calls for each

3 duty cycle; and encounters found on one duty cycle that had the same, longer or shorter duration

4 than their corresponding encounters found on the other duty cycle.

\begin{tabular}{|ll|cc|}
\hline Duty cycle (with LTSA) & \multicolumn{2}{|c|}{$\mathbf{1 / 3}$} & $\mathbf{2} 3$ \\
\hline Number of samples in dataset & Total & 1488 & 2976 \\
\hline \multirow{2}{*}{$\begin{array}{l}\text { Number of samples containing killer } \\
\text { whale calls }\end{array}$} & Total & \multicolumn{2}{|c|}{206} \\
& Exclusive & $5(2 \%)$ & $115(56 \%)$ \\
& Common & \multicolumn{2}{|c|}{$86(42 \%)$} \\
\multirow{2}{*}{ Encounter duration } & Total & \multicolumn{2}{|c|}{30} \\
& Same & \multicolumn{2}{|c|}{$7(23 \%)$} \\
& Longer & $4(13 \%)$ & $19(64 \%)$ \\
\hline
\end{tabular}

5

6 


\section{List of Figures}

2

3 FIG. 1. (Color online) Study area. The red star shows the location where acoustic samples were

4 collected, on Swiftsure Bank.

5

6 FIG. 2. (Color online) LTSA (top) and spectrogram (bottom) corresponding to the portion of

7 acoustic data marked by the black rectangle. The LTSA shows an hour of Swiftsure AURAL

8 data. It includes humpback whale calls (left) and killer whale calls and echolocation clicks

9 (right). The spectrogram represents 10 seconds of data and shows S18 pulsed call from L pod

10 (Southern Resident community or J clan).

11

12 FIG. 3. (Color online) Examples of Resident and Transient acoustic encounters, based on a 1/3

13 duty cycle. The boxes represent 10-minute acoustic files, with their start time. Green boxes

14 represent samples with killer whale calls. White boxes represent samples without calls. When

15 Resident calls were identified, two samples with calls were considered to belong to the same

16 encounter when they were separated by less than 6 consecutive samples without calls (which

17 equal 3 hours of silence between detected calls). The first series of boxes illustrates one

18 encounter that lasted 4 hours and 10 minutes. The second series of boxes shows two encounters,

19 of 10 and 40 minutes respectively. When Transient calls were identified, two samples with calls

20 were considered to belong to the same encounter when they were separated by less than 3

21 consecutive samples without calls (this is 1.5 hours of silence between heard calls). The last

22 series of boxes represents two encounters, the first lasted 2 hours and 10 minutes and the second

2310 minutes. 
2 FIG. 4. Number of encounters with different identification status for each of the analyses. The

3 total number of encounters is shown in black. Encounters with positive ID are represented in

4 white. The total number of unidentified encounters is represented in gray. The hatched area

5 represents unidentified encounters due to missed samples. When there are more unidentified

6 encounters, they are due to the killer whale calls being too faint.

7

8 FIG. 5. Number of killer whale encounters (with corresponding percentage) that were detected

9 with 2/3 (top) and 1/3 (bottom) duty cycles, using LTSA as analyzing tool. The black area

10 represents the number of encounters that are the same in both duty cycles. The dotted area

11 represents number of encounters that were only detected in 2/3 duty cycle. The gray area

12 represents number of encounters that were only detected in 1/3 duty cycle. The white area

13 represents the number of "false positive" encounters; those extra encounters in 1/3 which belong

14 to larger encounters but have been separated in different smaller encounters due to applying the

15 definition after missing samples. $\mathrm{N}=29$ (top - or $2 / 3$ ) and 27 (bottom - or 1/3) encounters.

16

17 FIG. 6. Number of encounters with different identification status for each duty cycle. The total

18 number of encounters is shown in black. Encounters with positive ID are represented in white.

19 The total number of unidentified encounters is represented in gray. The hatched area represents

20 unidentified encounters due to missed samples. When there are more unidentified encounters,

21 they are due to the killer whale calls being too faint. 


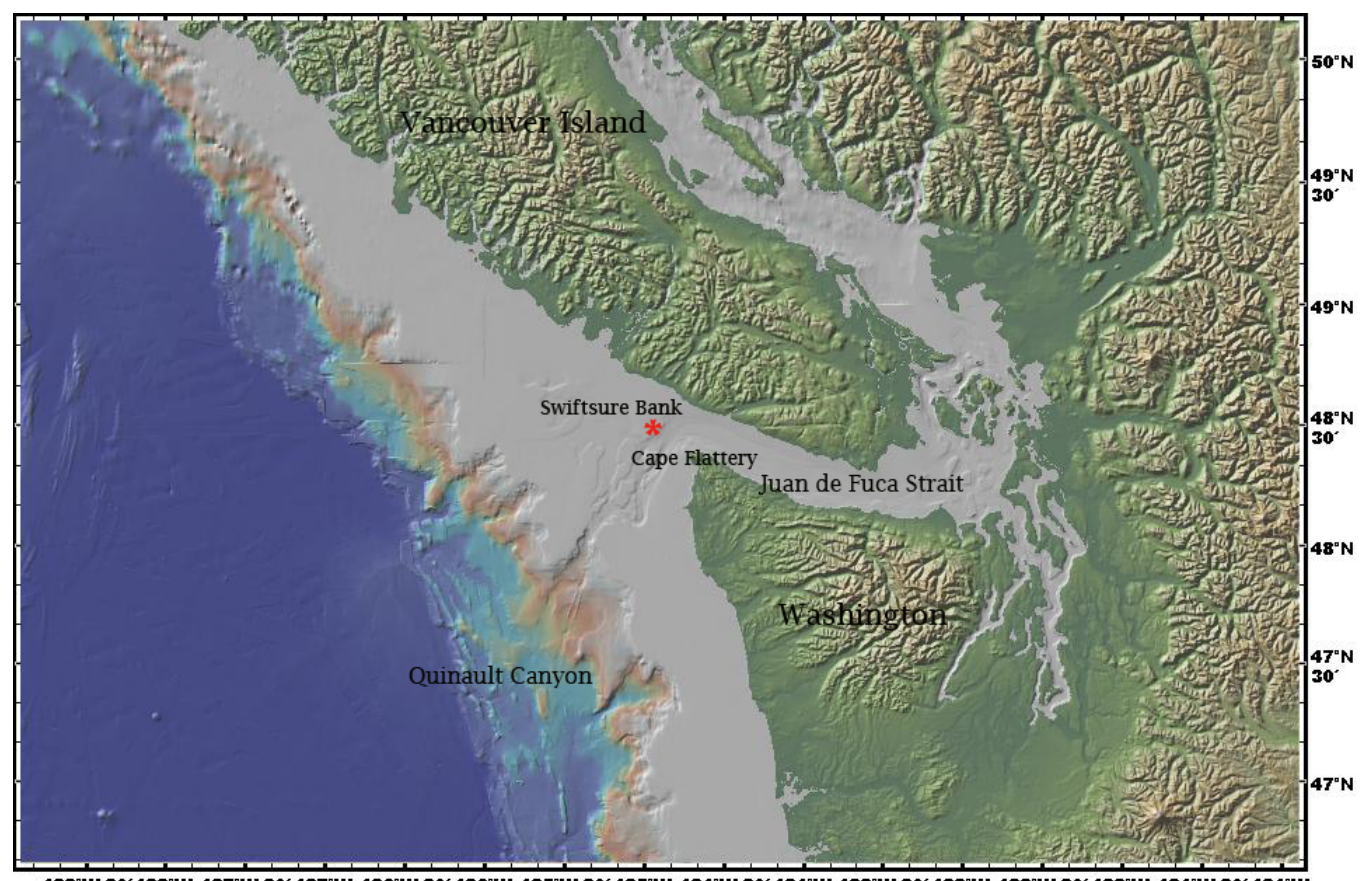

$128^{\circ} \mathrm{W} 30^{\circ} 128^{\circ} \mathrm{W} 127^{\circ} \mathrm{W} 30^{\circ} 127^{\circ} \mathrm{W} 126^{\circ} \mathrm{W} 30^{\circ} 126^{\circ} \mathrm{W} 125^{\circ} \mathrm{W} 30^{\circ} 125^{\circ} \mathrm{W} 124^{\circ} \mathrm{W} 30^{\circ} 124^{\circ} \mathrm{W} 123^{\circ} \mathrm{W} 30^{\circ} 123^{\circ} \mathrm{W} 122^{\circ} \mathrm{W} 30^{\circ} 122^{\circ} \mathrm{W} 121^{\circ} \mathrm{W} 30^{\circ} 121^{\circ} \mathrm{W}$ 

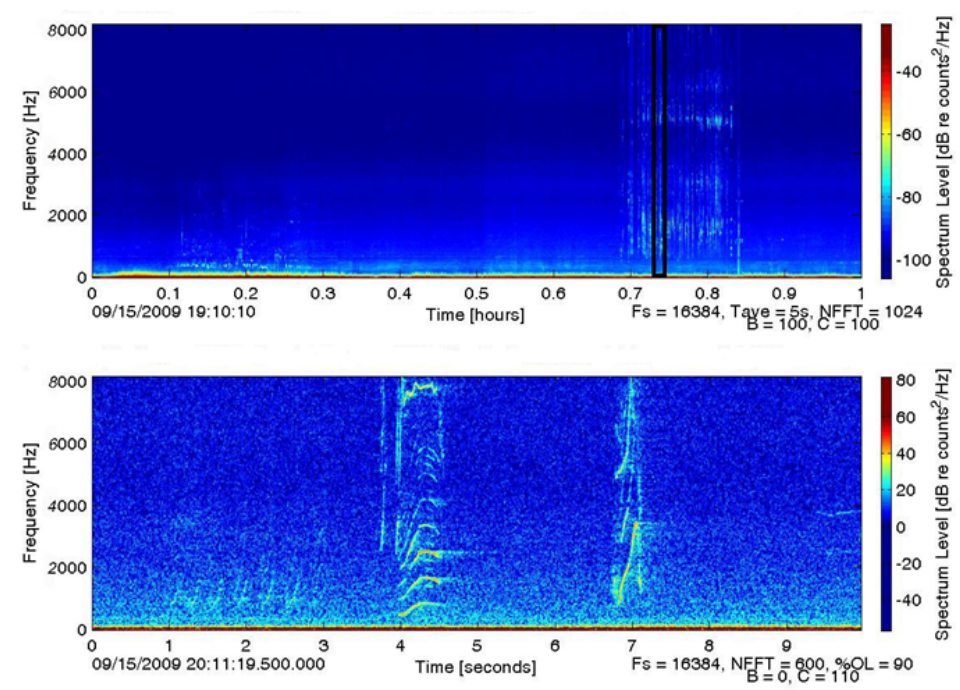


\section{Defining an 'encounter'}

- Residents (6 consecutive samples - 3h)

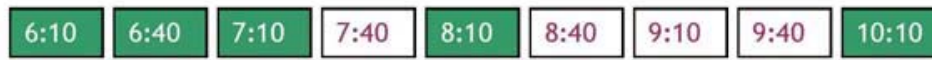

1 encounter. Duration $=6: 10-10: 20=4: 10$

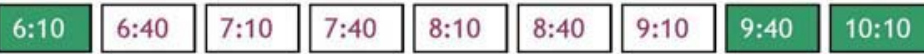

2 encounters. Duration $=6: 10-6: 20=0: 10$ and $9: 40-10: 20=0: 40$

- Transients ( 3 consecutive samples - 1.5h)

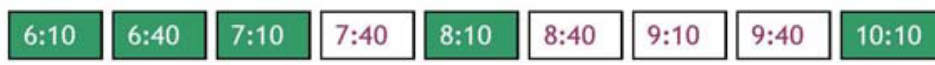

2 encounters. Duration $=6: 10-8: 20=2: 10$ and $10: 10-10: 20=0: 10$

Sample containing calls

Sample not containing calls 


\section{Encounter ID for $1 / 3$ duty cycle}

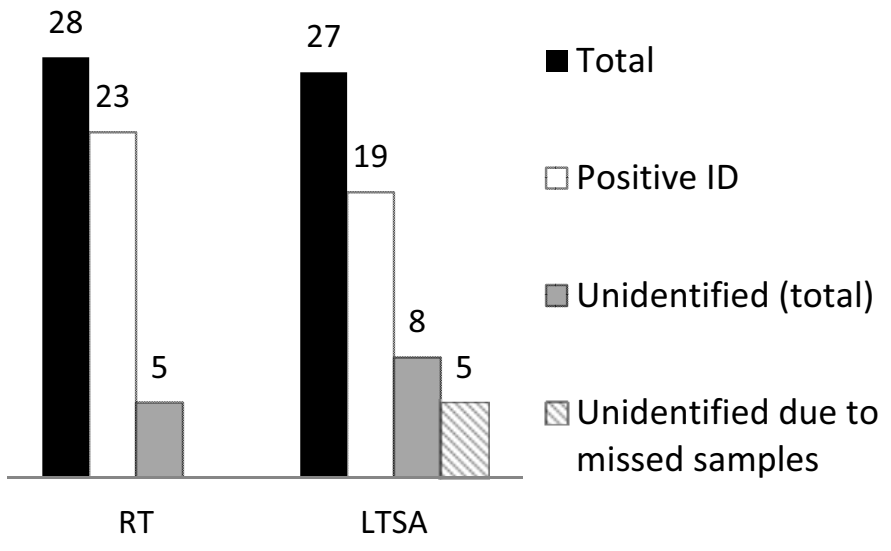




\section{Number of encounters $2 / 3$}

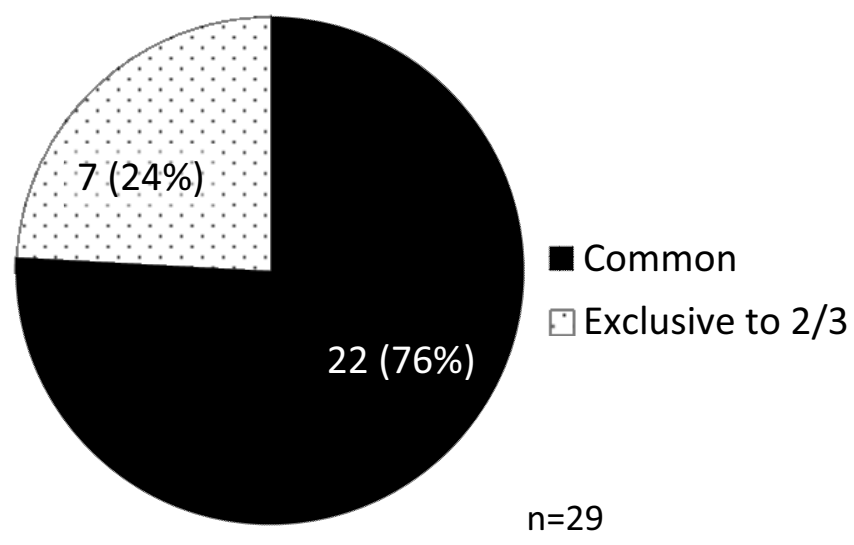

Number of encounters $1 / 3$

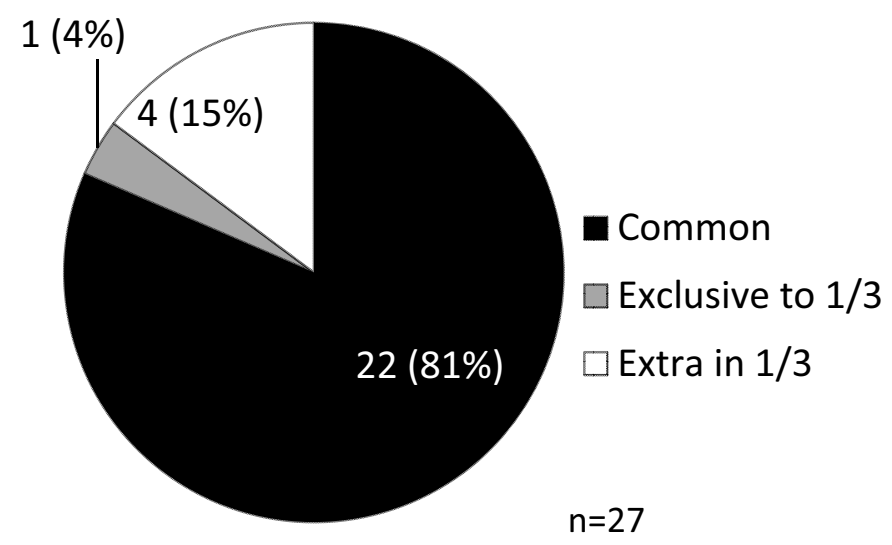




\section{Encounter ID for LTSA}

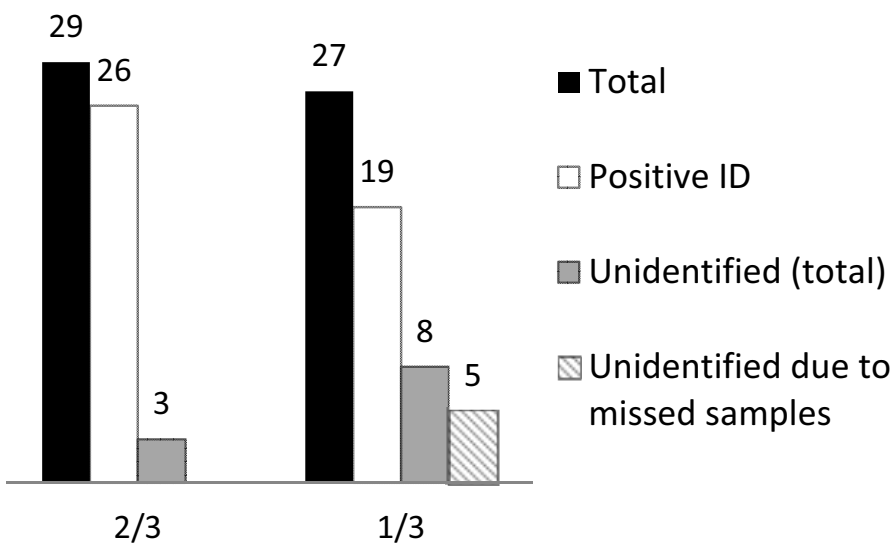

